\title{
Host choice of Phlebotomus orientalis (Diptera: Psychodidae) in animal baited experiments: a field study in Tahtay Adiyabo district, northern Ethiopia
}

Araya Gebresilassie ${ }^{1,2^{*}}$, Solomon Yared ${ }^{2,4}$, Essayas Aklilu', Oscar David Kirstein ${ }^{3}$, Aviad Moncaz $^{3}$, Habte Tekie , Meshesha Balkew ${ }^{4}$, Alon Warburg ${ }^{3}$, Asrat Hailu ${ }^{5}$ and Teshome Gebre-Michael ${ }^{4}$

\begin{abstract}
Background: Host choice and feeding success of sand fly vectors of visceral leishmaniasis $(V L)$ are important factors in understanding the epidemiology and for developing efficient control strategies. The aim of the present study was to determine the host preference of Phlebotomus orientalis in the VL focus of Tahtay Adiyabo district, northern Ethiopia.

Methods: Two separate experiments were conducted testing attraction of $P$. orientalis to humans, domestic animals, and small wild animals. The host choice of $P$. orientalis and other sand fly species was assessed using tent traps baited with seven different animals (human, cow, sheep, goat, donkey, dog and chicken) and a blank control. Baited traps were rotated every night in a Latin square design for two consecutive full rounds totaling 16 trap-nights. The second set of experiments tested attraction to small wild animals including; ground squirrel (Xerus rutilus), hare (Lepus sp.), gerbil (Tatera robusta) and spiny mouse (Acomys cahirinus). Animals were caged in standard rodent traps or cylindrical wire-mesh cages. The bait animals were placed in agricultural field and the attracted sand flies were collected using unlit CDC traps for 10 trapping nights. Sand fly specimens collected from each of the experiments were identified to species level and counted.

Results: Significant difference $(P<0.05)$ was observed in the attraction and feeding rate of $P$. orientalis to different baits. In the first experiment, cow-baited tent traps attracted the highest mean number of $P$. orientalis ( $m e a n=510$ flies). The engorgement rate of $P$. orientalis on donkey was the highest followed by cow, and much lower on goat, sheep, dog and chicken. In the case of smaller wild animals, more numbers of $P$. orientalis females were attracted to squirrels followed by hares, gerbils and the spiny rat. However, the engorgement rates for $P$. orientalis in the smaller animals were very low (1.08\%) compared with larger domestic animals (30.53\%).

Conclusion: The tendency of female $P$. orientalis to engorge in large numbers on certain species of domestic as well as wild animals strongly indicated that the species is primarily zoophilic in its host preference with feeding habits that may vary depending on the availability of hosts.
\end{abstract}

Keywords: Host attractiveness, Phlebotomus orientalis, Visceral leishmaniasis, Zoophilic sand flies

\footnotetext{
* Correspondence: shambe2006@yahoo.com

'Department of Zoological Sciences, Addis Ababa University, Addis Ababa,

Ethiopia

${ }^{2}$ Department of Biology, College of Natural Science, Jigjiga University, Jigjiga,

Ethiopia

Full list of author information is available at the end of the article
} 


\section{Background}

Ninety-eight countries and 3 territories on 5 continents are endemic for either of the two major forms of leishmaniasis: cutaneous leishmaniasis (CL), a disfiguring and stigmatizing disease, and visceral leishmaniasis (VL) or kala-azar, which is fatal if untreated [1,2]. In Ethiopia, VL caused by Leishmania donovani, is considered an emerging disease with an estimated incidence of 3,700 to 7,400 cases per year [2]. Highly VL endemic foci are in the south-west and the Humera and Metema lowlands in the north-west of the country [3,4]. However, recently increasing numbers of VL has been reported from previously non-endemic regions such as Libo Kemkem district of Amhara Regional State and Tahtay Adiyabo district in Tigray Regional State in Northern Ethiopia [5,6].

The various forms of leishmaniasis, including VL are transmitted by the bite of infected female sand flies of the genus Phlebotomus in the Old World and Lutzomyia in the New World [7,8]. Transmission of VL occurs when a sand fly acquires infection during feeding on an infected host and transmits the parasite during subsequent feeding after completion of the gonotrophic cycle, during which the parasite multiplies in the midgut and migrates to the foregut and mouthparts of the infected sand fly female. In southern Ethiopia and Kenya, the principal vector is $P$. martini which breeds and rests in termite mounds $[9,10]$, whereas in northern Ethiopia and eastern Sudan, $P$. orientalis is implicated as the vector inhabiting Acacia forests and cracking vertisols [11-13].

The host preferences of several sand fly species have been investigated mostly through the identification of the sources of bloodmeals using serological $[14,15]$ or molecular assays [16,17] and host attractiveness experiments [18-20]. Previously, the host preference of $P$. orientalis in Sudan and Ethiopia was determined by quantifying the host preferences using different animal baits $[20,21]$ or by identification of sources of bloodmeals by ELISA [12]. In eastern Sudan, it has been shown that $P$. orientalis is largely attracted to dogs, which is a suspected reservoir host for domestic transmission of VL in the area [13]. In the Humera-Metema plains of northwest Ethiopia, the host preference of $P$. orientalis appeared to be zoophilic, predominantly feeding on bovine blood [13]. These limited studies in East Africa might indicate P. orientalis to be an opportunistic feeder; however, detailed studies are needed to understand the natural host preference profile of $P$. orientalis and other sand fly species and their possible epidemiological significance of both domestic and wild animals in the transmission dynamics of VL.

Taking into account the fragmentary information available on the feeding habit of $P$. orientalis, we designed an experiment to determine the relative host attractiveness and feeding success of $P$. orientalis on domestic and small wild mammals in a VL endemic area of north Ethiopia.

\section{Methods}

\section{Study area}

The study area has previously been described elsewhere [22]. Briefly, the investigation was conducted in the Geza Adura sub-village in the Tahtay Adiyabo district (14.22'27" N/37 $44^{\prime} 36^{\prime \prime}$ E) in Tigray Regional State, Northern Ethiopia, which is situated $1,117 \mathrm{~km}$ north of Addis Ababa. The climate is generally sub-tropical-arid, with an extended dry period of nine to ten months (OctoberMay), experiencing only one rainy season (June-September) with a mean annual precipitation of about $600 \mathrm{~mm}$ (Ethiopian National Meteorological Agency). April and May are the warmest months with an average temperature of $39^{\circ} \mathrm{C}$ and January is the coldest with an average temperature of $14.2^{\circ} \mathrm{C}$.

In different villages of Tahtay Adiyabo district, large numbers of domestic animals including cattle, sheep, goats, donkeys, camels, dogs and chickens are kept. Moreover, a wide range of wild animals such as hares, ground squirrels, rodents, reptiles, white-tailed mongoose and foxes are either occasionally or commonly seen.

\section{Host choice experiments}

The two independent host choice studies under field conditions were conducted between March and April 2013 in rotational experimental design in which wild sand flies were given the choice of different animal baits. The experiments were conducted in an open agricultural field, where there were no potential bloodmeal source animals (cattle, sheep, goats, donkeys, camels, dogs, chickens and other small wild animals) near the test traps for at least 400-450 meters.

\section{Experiment I}

The experiment was conducted using wild sand flies offered a choice of seven baits (human volunteer, cow, sheep, goat, donkey, dog and chicken) and control (without baits) assigned in tent traps. Each tent trap (dimension: $2.5 \mathrm{~m} \times 2.5 \mathrm{~m} \times 2.5 \mathrm{~m}$ ) was constructed from transparent sand fly-proof netting supported by four rectangular metal frames and four metal poles to firmly fix them to the ground when installed (Figure 1-A). Six cone-shaped openings were fitted on the sides of the tent and the tent was raised a few centimeters above the ground to allow entry of host seeking sand flies (Figure 1-B). One side of the net had a long zipped slit (top to bottom) to enable entry and exit of host plus the participant to aspirate sand flies from inside the trap. The tent trap design was based on a prototype used previously to assess sand fly attraction behavior in Colombia [19].

The animals were tethered in the center of the tent while the human volunteer slept on a cot protected by an untreated sand fly-proof mosquito net inside the tent trap. Baited tent trap and an un-baited control trap were 


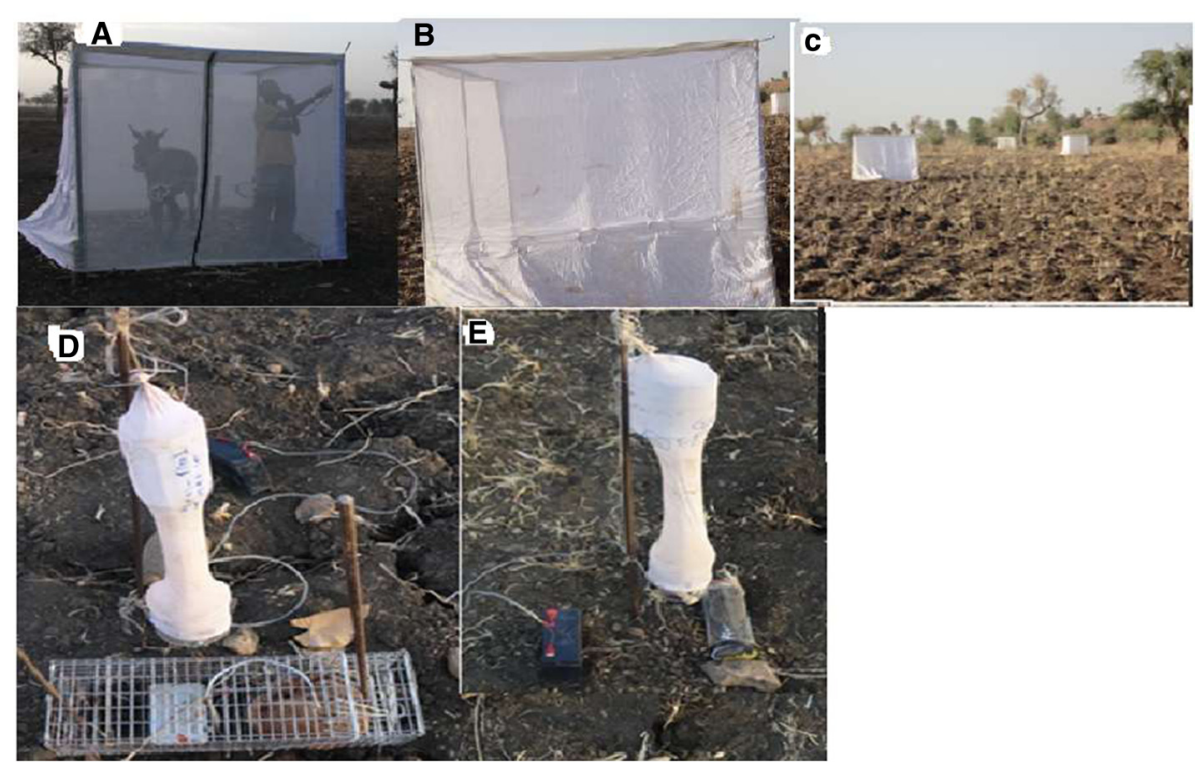

Figure 1 Host attractiveness experiments. A: Tent trap with animal bait. B: Cones fitted to one side of the tent. C: Arrangement of animal baits in the field. D: Cage trap baited with ground squirrel. E: Cage baited with rodent species.

arranged in a circular manner at a distance of about 30 meters from each other (Figure 1-C). The baits and unbaited traps rotated every night between different positions to eliminate location or site variations in sand fly abundance. Two replicate collections were performed on a total of 16 trapping nights. Some of the animals were provided with grass and straw to calm them down for the nightlong session. Collection of trapped sand flies from the interior walls and the roof of the tent traps was performed early in the mornings (06:30-08:00 hours) by three to four trained and experienced collectors (one person/net) using mouth aspirators while the animals were still inside the net to prevent sand flies from escaping. The collected sand flies were placed in small Barraud cages, each labeled corresponding to the host until processing in the field laboratory. Blood-fed females were separately sorted out and all sand fly specimens were preserved in $70 \%$ ethanol for later identification to species.

\section{Experiment II \\ Trapping small animals and evaluation of attractiveness to sand flies}

Sherman-live traps and Tomahawk collapsible traps were used for trapping small animals needed for conducting host choice experiments. Traps baited with peanut butter were set near rock crevices, farm fields, rodent burrows and visible animal paths at night and at day time, and were checked for catches in the morning and in the evening, respectively. The only animals captured in this way were ground squirrel (Xerus rutilus), gerbil (Tatera robusta) and Cairo spiny mouse (Acomys cahirinus). Hares (Lepus sp.) were captured by chasing them from their hidings in the bush.

Square box traps $(30 \mathrm{~cm} \times 30 \mathrm{~cm} \times 30 \mathrm{~cm})$ with entrance brass screen cones on the three sides were locally constructed based on the design of Turner and Hoogstraal [21], and baited with the above animals (each restrained in a cylindrical wire mesh cage) were used for the experiment. However, these traps failed to catch sand flies. Therefore, as an alternative approach, the host choice experiment was conducted by placing modified CDC traps in an up-draft position after removing the light bulbs. These were set up in caged animals and a blank cage as control (Figures 1 D-E). The unlit CDC traps were placed with their opening $5 \mathrm{~cm}$ above each animal. The respective sizes of the rectangular metal wire cages used for the hare and ground squirrel were $40 \times 20 \times$ $20 \mathrm{~cm}^{3}$ and $12 \times 10 \times 8 \mathrm{~cm}^{3}$, respectively. The smaller rodents were kept inside a cylindrical wire mesh cage $(18 \mathrm{~cm} \times 6 \mathrm{~cm})$ with a metal lid at both ends. Like experiment one, caged animal baits and the blank control were placed in a circular manner at a distance of $30 \mathrm{~m}$ from each other. Experimental sessions started $1 \mathrm{~h}$ before sunset and terminated $1 \mathrm{~h}$ after sunrise, the following morning. The experiment was repeated 10 times totaling 10 trapping nights per bait and the animals were rotated between the different positions as above. In the mornings, sand fly specimens caught in the traps were collected using mouth aspirators, placed in separate Barraoud cages and transported to the field laboratory. Females were separated into fed and unfed, and preserved in $70 \%$ ethanol for later identification to species level. 


\section{Sand fly identification}

Collected sand fly specimens were mounted on microscope slides in Hoyer's medium with their heads facing down and separated from thoraces and abdomens. The species were identified based on appropriate keys and other published materials [23-25].

\section{Ethical considerations}

Informed consent was obtained from all human volunteers who participated in the host attractiveness experiments. Moreover, the experiments involving human volunteers and animals, described in this report, were ethically approved by the ethical review committee at the Medical Faculty, Addis Ababa University and the National Research Ethics Review Committee at the Ethiopian Ministry of Science and Technology. Moreover, fieldworks carried out in this study conformed to the International Guiding Principles for Biomedical Research Involving Animals developed by the Council for International Organizations of Medical Sciences and with the Standards for Human Care and Use of Laboratory Animals.

\section{Data analysis}

Prior to data analysis, sand fly numbers were transformed to $\log _{10}(x+1)$ to fit normal distribution and control the variance. A univariate analysis of variance (ANOVA) was used to compare the mean number of $P$. orientalis attracted to different animal baits and control traps. Tukey's Studentized test post hoc analysis was utilized to ascertain the extent of the difference between the groups in cases where ANOVA was significant. Probabilities of the $F$ tests were at $\alpha=0.05$ level. The non-parametric equivalent test (Kruskal-Wallis test) was used when data did not conform to the normal distribution. For non-parametric comparisons, multiple-MannWhitney $U$-test was used and, $p$-values were adjusted with the Bonferroni correction to adjust for the inflation of type I errors when several Mann-Whitney tests were performed [26]. All statistical analyses were carried out using IBM SPSS statistics, version 19 for Windows (SPSS Inc., Chicago, IL, USA) and Microsoft $^{\circ}$ Office Excel 2007.

\section{Results}

\section{Host attractiveness for $P$. orientalis and other sand flies}

In experiment one involving domestic animals and human, a total of 21,144 sand flies belonging to six species of Phlebotomus and seven species of Sergentomyia were collected and identified (Table 1). Of these, 13,764 were males and 7,380 were females. The most abundant species was $P$. orientalis (54.36\%) followed by $S$. africana (25.24\%) of all collections.

There were significant differences in the mean numbers of sand fly species caught by different baited traps
(ANOVA, $\mathrm{F}_{(d f=7)}=67.93, P<0.05$, Table 2). All hosts, except chicken, attracted considerably more sand flies than the controls (Table 2). Increased attractions in decreasing order of magnitude were found in cow-baited, donkey-baited and human-baited tents. The cow- and donkey-baited tents had significantly higher attractions than all the other baits $(P<0.05)$.

Animal baits differed substantially in their attractiveness to female and male P. orientalis (Table 3, KruskalWallis test, $P<0.05)$. Cow-baited traps collected notably higher mean number of $P$. orientalis (mean $=510$ flies $/$ tent trap) than other baits and control traps. However, donkey-baited traps attracted the highest mean number of $P$. orientalis females $($ mean $=82.69)($ Table 3$)$ though it was not significantly different from cow (MultipleMann Whitney $U$-test, $P>0.01$ ). Human bait was the third most effective attractant for collecting large numbers of $P$. orientalis females followed by sheep and goat, respectively. Dog and chicken-baited traps were the least attractive to $P$. orientalis females with no statistical difference between them and the control (Multiple-Mann Whitney $U$-test, $P>0.01$ ) (Table 3 ).

In experiment two, comparing the attractiveness of small wild animals, 9,015 sand fly specimens (males: 3,831; females: 5,184 ) representing eleven species in two genera were captured (Table 4). As in experiment one, P. orientalis was the dominant species comprising $81.8 \%$ of the catch followed by $S$. africana (10.1\%). There was a significant difference between the baits and the control (ANOVA, $\mathrm{F}_{(d f=4)}=23.16, P<0.05$; Figure 2). The mean number of sand flies attracted to ground squirrel was higher than that attracted to hare-baited traps, though these differences were not significantly different $(P>0.05)$. There was no statistically significant $(P>0.05)$ differential sand fly attraction between the spiny mouse (A. cahirinus) and gerbil (T. robusta).

Analysis of variance (ANOVA) revealed that cagedanimals differed in their attractiveness to both female and male $P$. orientalis $\left(\mathrm{F}_{(d f=4)}=35.19 ; P<0.05\right.$; Table 5$)$. Higher mean numbers of $P$. orientalis females were attracted to ground squirrel than other baits and control traps $(P<0.05)$. The hare was the second attractive animal to $P$. orientalis females, followed by $T$. robusta and $A$. cahirinus with insignificant differences in their mean numbers.

\section{Engorgement rates}

In experiment one, of the total 6,239 host-seeking $P$. orientalis females trapped in baited-tent traps excluding human bait, $30.53 \%$ were freshly engorged. The mean numbers of blood engorged sand fly specimens differed among the other six hosts (Kruskal-Wallis test, $P<0.05$, Table 6). P. orientalis fed most successfully on donkey (Mean $=78.56$ engorged flies). Cow was the second preferred host. Conversely, this species fed less successfully 
Table 1 Sand fly species captured in tent traps baited with different domestic animals or human volunteer in agricultural fields at Tahtay Adiyabo district

\begin{tabular}{|c|c|c|c|c|c|c|c|c|c|}
\hline \multirow{3}{*}{ Sand fly species } & \multicolumn{8}{|l|}{ Baits } & \multirow{3}{*}{ Total } \\
\hline & Cow & Donkey & Human & Sheep & Goat & Dog & Chicken & Control & \\
\hline & $M / F$ & $M / F$ & $M / F$ & $M / F$ & $M / F$ & $M / F$ & $M / F$ & $M / F$ & \\
\hline P. orientalis & $5753 / 855$ & $1661 / 1323$ & $458 / 595$ & $344 / 80$ & $213 / 56$ & $67 / 39$ & $20 / 60$ & $16 / 7$ & 11,493 \\
\hline P. rodhani & $0 / 0$ & $0 / 0$ & $0 / 0$ & $0 / 0$ & $4 / 0$ & $0 / 0$ & $0 / 0$ & $0 / 0$ & 4 \\
\hline P. lesleyae & $1 / 4$ & $1 / 4$ & $0 / 9$ & $0 / 2$ & $5 / 5$ & $0 / 1$ & $0 / 2$ & $1 / 1$ & 36 \\
\hline P. bergeroti & $0 / 0$ & $0 / 0$ & $0 / 0$ & $0 / 0$ & $4 / 0$ & $0 / 0$ & $0 / 0$ & $0 / 0$ & 4 \\
\hline P. martini & $0 / 0$ & $0 / 0$ & $11 / 11$ & $0 / 0$ & $4 / 0$ & $0 / 0$ & $0 / 0$ & $0 / 0$ & 26 \\
\hline P. heischi & $0 / 1$ & $0 / 0$ & $0 / 0$ & $0 / 0$ & $4 / 0$ & $0 / 0$ & $0 / 0$ & $0 / 0$ & 5 \\
\hline S. africana & $305 / 198$ & $278 / 203$ & $190 / 258$ & $568 / 286$ & $507 / 257$ & $599 / 250$ & $553 / 155$ & $650 / 79$ & 5,336 \\
\hline S. schwetzi & $367 / 526$ & $433 / 756$ & $112 / 105$ & 204/181 & 109/290 & $64 / 173$ & $21 / 37$ & $7 / 30$ & 3,415 \\
\hline S. clydei & $27 / 97$ & $23 / 114$ & $4 / 5$ & $12 / 76$ & $23 / 90$ & $14 / 45$ & $1 / 1$ & $3 / 3$ & 538 \\
\hline S. bedfordi group & $10 / 8$ & $12 / 10$ & $5 / 28$ & $6 / 6$ & $5 / 9$ & $15 / 16$ & $2 / 3)$ & $1 / 0$ & 146 \\
\hline S. antennata group & $11 / 12$ & $12 / 16)$ & $7 / 6$ & $14 / 9$ & $4 / 9$ & $5 / 15$ & $6(/ 2$ & $5 / 5$ & 137 \\
\hline S. calcarata & $0 / 0$ & $0 / 0)$ & $0 / 0$ & $0 / 0$ & $0 / 0$ & $0 / 1$ & $0 / 0$ & $0 / 0$ & 1 \\
\hline S. squamipleuris & $0 / 0$ & $0 / 0$ & $0 / 0$ & $1 / 0$ & $0 / 0$ & $0 / 0$ & $1 / 0$ & $1 / 0$ & 3 \\
\hline Total & $6474 / 1701$ & $2420 / 2426$ & $787 / 1017$ & $1149 / 640$ & $882 / 716$ & $764 / 540$ & $604 / 216$ & $684 / 24$ & 21,144 \\
\hline
\end{tabular}

$\mathrm{M}=$ Male; $\mathrm{F}=$ Female.

on goat, sheep, dog and chicken in decreasing order with no significant difference (multiple-Mann Whitney $U$ test, $P>0.01)$.

In experiment two involving small wild animals, only $1.08 \%(48 / 4,448$ flies $)$ were found with bloodmeals. Although the number of engorged $P$. orientalis was small, there were significant differences in the mean numbers of engorged females of sand fly specimens between the four bait species (ANOVA, F $(d f=3)=5.37 ; P=0.005$, Figure 3). Ground squirrel and hare were the preferred hosts over the two rodent species.

Table 2 Mean numbers ( \pm SE) of sand fly specimens captured in tent traps baited with different domestic animals and human host in agricultural fields at Tahtay Adiyabo district

\begin{tabular}{ll}
\hline Bait types & Mean number \pm SE of sand flies collected/ trap \\
\hline Cow & $510.93 \pm 75.87 a$ \\
Donkey & $302.94 \pm 45.74 b$ \\
Human & $112.81 \pm 9.60 c$ \\
Sheep & $111.81 \pm 20.94 c$ \\
Goat & $99.88 \pm 11.52 c$ \\
Dog & $81.50 \pm 20.15 c$ \\
Chicken & $51.25 \pm 10.96 d$ \\
Control & $50.50 \pm 8.61 d$
\end{tabular}

Mean values followed by the same letter on the same line are not significantly different $(P<0.05)$.

\section{Sex ratio}

In experiment one, the total number of $P$. orientalis females caught by animal baited traps and control traps combined was smaller than that of males (7,380 female: 13,764 male). The overall female/male sex ratio for $P$. orientalis species was 0.54 , which was significantly in favour of males $(P<0.05)$. It was only in human-baited traps that the female/male ratio $(=1.3)$ was in favour of females (Table 7).

In experiment two, the overall female/male sex ratio of $P$. orientalis attracted to host species and control traps

Table 3 Mean numbers ( \pm SE) of female and male $P$. orientalis attracted to tent traps baited with different domestic animals and human host

\begin{tabular}{lll}
\hline Bait types & \multicolumn{2}{l}{ Mean number \pm SE of sand flies collected/tent trap } \\
\cline { 2 - 3 } & Female & Male \\
\hline Cow & $53.44 \pm 3.19 \mathrm{ab}$ & $359.56 \pm 54.25 \mathrm{a}$ \\
Donkey & $82.69 \pm 10.81 \mathrm{a}$ & $103.81 \pm 21.16 \mathrm{~b}$ \\
Human & $37.19 \pm 2.82 \mathrm{C}$ & $28.63 \pm 3.24 \mathrm{c}$ \\
Sheep & $5.00 \pm 1.12 \mathrm{~d}$ & $21.50 \pm 4.79 \mathrm{~cd}$ \\
Goat & $3.5 \pm 1.19 \mathrm{de}$ & $13.31 \pm 3.34 \mathrm{~d}$ \\
Dog & $2.44 \pm 0.99 \mathrm{ef}$ & $4.19 \pm 1.52 \mathrm{e}$ \\
Chicken & $0.38 \pm 0.25 \mathrm{f}$ & $1.25 \pm 0.61 \mathrm{e}$ \\
Control & $0.44 \pm 0.12 \mathrm{f}$ & $1.00 \pm 0.45 \mathrm{e}$
\end{tabular}

Mean values followed by the same letter on the same line are not significantly different $(P<0.01$; Multiple-Mann Whitney $U$-test). 
Table 4 Number of sand fly species attracted to different small wild mammals in agricultural fields at Tahtay Adiyabo district

\begin{tabular}{|c|c|c|c|c|c|c|c|c|c|c|}
\hline \multirow{3}{*}{ Sand fly species } & \multicolumn{10}{|l|}{ Baits } \\
\hline & \multicolumn{2}{|c|}{ Squirrel } & \multicolumn{2}{|l|}{ Hare } & \multicolumn{2}{|c|}{ Gerbil } & \multicolumn{2}{|c|}{ Spiny mouse } & \multicolumn{2}{|c|}{ Control } \\
\hline & $\bar{M}$ & $F$ & $\bar{M}$ & $F$ & $\bar{M}$ & $F$ & $\bar{M}$ & $\mathrm{~F}$ & $\bar{M}$ & $F$ \\
\hline P. orientalis & 955 & 2054 & 917 & 906 & 394 & 854 & 523 & 634 & 48 & 89 \\
\hline P. rodhaini & 5 & 5 & 11 & 11 & 6 & 7 & 2 & 3 & 0 & 2 \\
\hline P. lesleyae & 2 & 2 & 0 & 1 & 0 & 2 & 3 & 2 & 0 & 1 \\
\hline P. martini & 1 & 0 & 0 & 0 & 0 & 0 & 0 & 0 & 0 & 0 \\
\hline P. heischi & 1 & 2 & 3 & 2 & 0 & 0 & 1 & 1 & 0 & 0 \\
\hline S. africana & 109 & 28 & 243 & 27 & 188 & 26 & 98 & 54 & 112 & 26 \\
\hline S. schwetzi & 8 & 18 & 11 & 28 & 7 & 14 & 18 & 20 & 6 & 65 \\
\hline S. clydei & 26 & 149 & 15 & 57 & 12 & 37 & 18 & 20 & 5 & 5 \\
\hline S. bedfordi group & 6 & 1 & 6 & 0 & 11 & 0 & 3 & 3 & 4 & 2 \\
\hline S. antennata group & 8 & 3 & 7 & 7 & 22 & 2 & 9 & 9 & 7 & 4 \\
\hline S. adleri & 0 & 0 & 0 & 0 & 0 & 1 & 0 & 0 & 0 & 0 \\
\hline Total & 1,121 & 2,262 & 1,213 & 1,039 & 640 & 943 & 675 & 746 & 182 & 194 \\
\hline
\end{tabular}

$\mathrm{M}=$ Male; $\mathrm{F}=$ Female.

was 1.6, which was significantly different (ANOVA, F $(d f=3)=3.66 ; P=0.024)$, showing predominantly female sand fly attractiveness by all hosts except hare baited traps (Table 7).

\section{Discussion}

Host preferences of vectors represent an important aspect of the bionomics of vector-borne disease dynamics, directly affecting the magnitude of disease transmission. The experiments described here demonstrated that $P$. orientalis females were attracted and engorged more frequently upon certain hosts than others. Host attractiveness to sand flies varies temporally and spatially; phenomena which could be associated with host body surface area, dosespecific responses to ubiquitous cues such as $\mathrm{CO}_{2}$ and host-specific odors [27-29].

In this experiment involving domestic animals and humans, higher numbers of $P$. orientalis females were attracted and engorged on donkey and cow than other hosts. Similar results have been previously recorded for Old as well as New World vectors [13,27,30]. These constitute favored bloodmeal sources for female $P$. orientalis as demonstrated in direct bloodmeal analysis by ELISA and PCR (Gebresilassie et al., in preparation). The accessibility

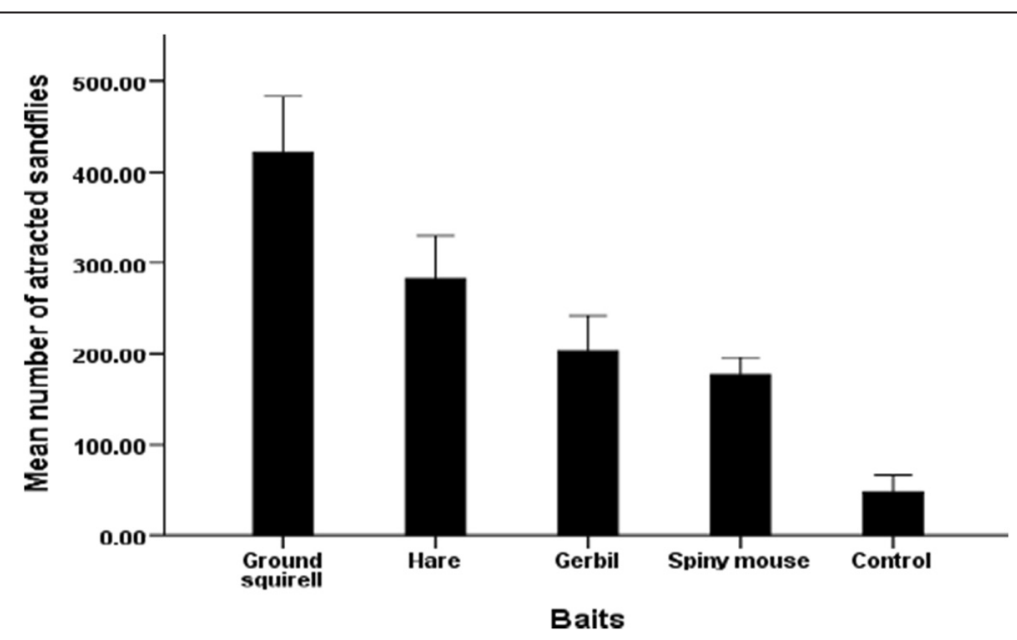

Figure 2 Mean numbers ( \pm standard errors) of sand fly specimens captured in traps baited with different small wild mammals at Tahtay Adiyabo district. 
Table 5 Mean numbers ( \pm SE) of female and male $P$. orientalis attracted to traps baited with different small wild mammals

\begin{tabular}{lll}
\hline Bait types & \multicolumn{2}{l}{ Mean number \pm SE of sand flies captured/CDC trap } \\
\cline { 2 - 3 } & Female & Male \\
\hline Ground squirrel & $256.75 \pm 44.91 \mathrm{a}$ & $119.38 \pm 19.25 \mathrm{a}$ \\
Hare & $113.25 \pm 18.72 \mathrm{~b}$ & $114.63 \pm 18.87 \mathrm{ab}$ \\
Spiny mouse & $79.25 \pm 14.05 \mathrm{~b}$ & $65.37 \pm 7.77 \mathrm{~b}$ \\
Gerbil & $106.75 \pm 28.26 \mathrm{~b}$ & $49.25 \pm 11.75 \mathrm{bc}$ \\
Control & $12.75 \pm 2.91 \mathrm{c}$ & $6.00 \pm 1.53 \mathrm{~d}$ \\
\hline
\end{tabular}

Mean values followed by the same letter on the same line are not significantly different $(P<0.05)$.

of bovine blood hosts to questing $P$. orientalis females in the peri-domestic habitats may provide zooprophylactic barrier potentially reducing human-vector contact, or it may aggravate the risk of VL infection. Studies in Nepal [31] showed that ownership or proximity of cattle was associated with significant protection of VL infection, whereas in India VL appeared to increase for those living in close proximity to cattle [32]. In Sudan, Mukhtar et al. [33] were able to detect the presence of anti-Leishmania antibodies in donkeys, cows, and goats. A recent study in Nepal also detected the presence of Leishmania DNA in domestic animals such as goats, cattle, and buffaloes, several months after the active transmission season [34]. Similarly, $L$. donovani DNA was detected in cattle, donkeys, sheep, and goats in cross-sectional studies in our study area (Rhoussova et al., in preparation). Therefore, the role of cattle in the epidemiology of VL in our study area requires detailed and systematic investigation.

The current study as well as a previous study from Sudan has shown that humans are attractive hosts to $P$. orientalis [35]. Importantly, bloodmeal determination of engorged wild-caught females of $P$. orientalis in the same area revealed that $8.5 \%$ of females contain human blood origins (Gebresilassie et al., in preparation). This finding supports the likelihood that $P$. orientalis is the vector of $\mathrm{VL}$ in these parts of East Africa since attraction to humans by a sand fly vector is a minimum requirement for disease transmission [36].

Relatively few $P$. orientalis females were attracted to and engorged upon sheep, goat, dog or chicken (Table 3). In agreement of this finding, bloodmeal analyses of engorged wild-caught females in the same area revealed that only a small proportion had fed upon these hosts ([13], Gebresilassie et al., in preparation). Thus, our results do not support a role of goats, sheep, dogs and chickens as food source for $P$. orientalis as suggested in previous studies from Kenya [18,30] and Sudan [20] showing that these animals were highly attractive to $P$. martini and $P$. orientalis. These variations might be due to differences in the innate behavior of the sand fly species involved, and the experimental design used. Parasitological studies in Kenya also confirmed that sheep could not support the infection of $L$. donovani $[37,38]$.

In the experiment using small mammals, $P$. orientalis was more attracted to ground squirrels ( $X$. rutilus), followed by hares (Lepus sp.), gerbils (T. robusta) and spiny mice (A. cahirinus). However, the feeding rates in all cases were very low compared with baited-tent traps, probably because the attracted sand flies in this case were trapped before they had sufficient time to feed on the hosts. Rejection does not seem to be the case, since these small mammals are the common wild animals that $P$. orientalis would encounter in the wild including fissures in vertisols and fields, where humans and domestic animals are absent. It has previously been observed that wild-caught $P$. orientalis and $P$. martini had fed upon squirrels and rodents [14,39-41]. Different species of rodents have been identified as the reservoir hosts of Leishmania spp. in various parts of the world $[11,42,43]$ and hares (L. granatensis) were recently incriminated as reservoir hosts of $L$. infantum in

Table 6 Number and percentage of female sand fly species attracted and engorged on different domestic animals baits

\begin{tabular}{|c|c|c|c|c|c|c|}
\hline \multirow[t]{3}{*}{ Sand fly species } & \multicolumn{6}{|c|}{ Percentage of blood fed females } \\
\hline & Cow & Donkey & Sheep & Goat & Dog & Chicken \\
\hline & $\%$ fed & $\%$ fed & $\%$ fed & $\%$ fed & $\%$ fed & $\%$ fed \\
\hline P. orientalis & $72.8(855)$ & $92.6(1323)$ & $27.5(80)$ & $44.6(56)$ & $18(39)$ & $66.7(6)$ \\
\hline P. lesleyae & $0(4)$ & $0(4)$ & $0(2)$ & $0(5)$ & $0(1)$ & $0(2)$ \\
\hline P. heischi & $0(1)$ & $0(0)$ & $0(0)$ & $0(0)$ & $0(0)$ & $0(0)$ \\
\hline S. africana & $0(198)$ & $0(203)$ & $0(286)$ & $0(257)$ & $0(250)$ & $0(155)$ \\
\hline S. schwetzi & $1.9(526)$ & $0.7(756)$ & $0(181)$ & $0.7(290)$ & $0(173)$ & $0(37)$ \\
\hline S. clydei & $3.1(97)$ & $0(114)$ & $0(76)$ & $2.2(90)$ & $0(45)$ & $0(1)$ \\
\hline S. bedfordi group & $0(8)$ & $0(10)$ & $0(6)$ & $0(9)$ & $0(16)$ & $0(13)$ \\
\hline S. antennata group & $0(12)$ & $0(16)$ & $0(9)$ & $0(9)$ & $0(15)$ & $0(2)$ \\
\hline
\end{tabular}

Figures in brackets denote total number of sand fly females caught in various animal baited tent traps. 


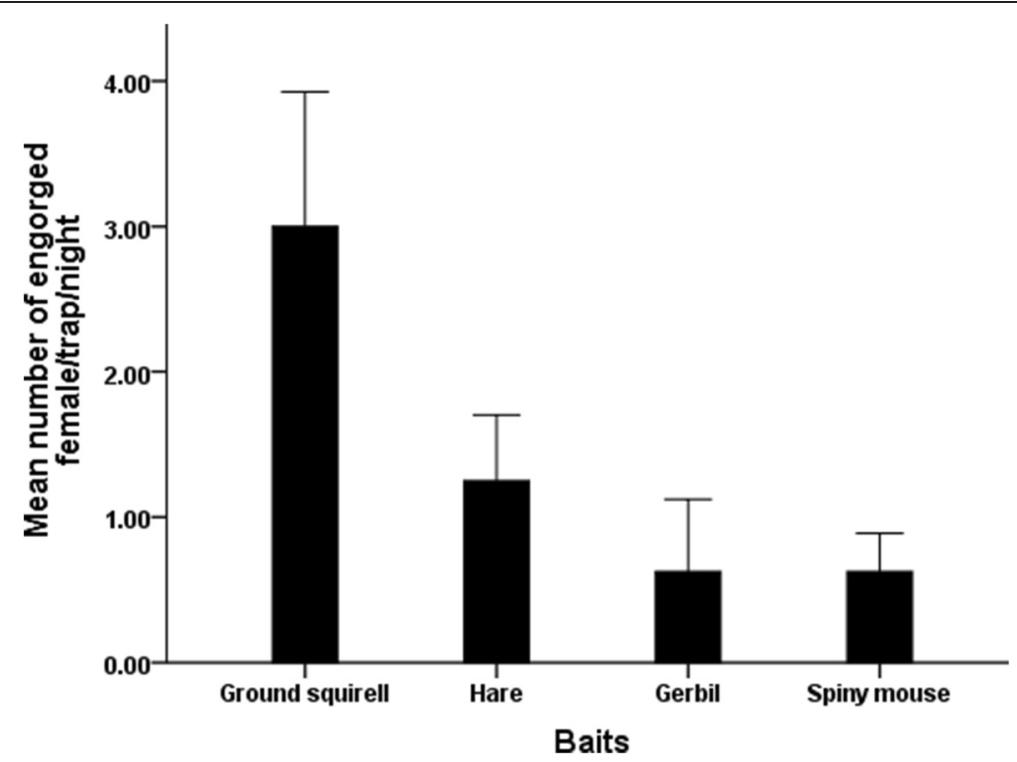

Figure 3 Mean numbers ( \pm standard errors) of engorged female $P$. orientalis on different species of wild small mammals.

Spain $[44,45]$. The exact role of these animals in the epidemiology of VL in the study area remains to be explored.

Male sand flies predominated in the tent traps-baited with large domestic animals, indicating that mating occurs on the host. A swarming male population of $P$. argentipes and Lu. longipalpis were described close to animals used as bloodmeal sources by the females [46-48]. Unlike the larger domestic animals, however, the sex ratio in smaller wild animals was female biased except for hares. This higher proportion of female sand flies on smaller wild animals might be associated with the differences in body size of the animal baits or the design of trapping methods followed in both experiments.

\section{Conclusions}

The tendency of female $P$. orientalis to engorge in large numbers on certain species of domestic as well as wild

Table 7 Sex ratio (F/M) of $\boldsymbol{P}$. orientalis females and males attracted to traps baited with different animal and human hosts

\begin{tabular}{llll}
\hline Bait types & & & \\
\hline Domestic animals & $\mathbf{F}_{\mathbf{M}}$ * & Small wild animals & F/M* $^{*}$ \\
\hline Cow & 0.15 & Ground squirrel & 2.15 \\
Donkey & 0.8 & Hare & 0.9 \\
Human & 1.3 & Spiny mouse & 1.21 \\
Sheep & 0.23 & Gerbil & 2.17 \\
Goat & 0.26 & Control & 1.85 \\
Dog & 0.58 & & \\
Chicken & 0.3 & & \\
Control & 0.44 & & \\
\hline
\end{tabular}

${ }^{*} \mathrm{~F} / \mathrm{M}=$ proportion of female: male $P$. orientalis. animals strongly indicated that the species is primarily zoophilic in its host preference with feeding habits that may vary depending on the availability of hosts. In addition, increased predilection of $P$. orientalis to bite cattle, the predominant domestic animal in our study area, may have a protective or increased exposure to VL, which requires further investigations. This zoophilic behavior can, however, be exploited for killing sand flies using pyrethroid insecticide treated animals [49]. Furthermore, detailed parasitological and xenodiagnostic studies, may shed some light on the epidemiology of kala-azar facilitating the implementation of effective control strategies.

Competing interests

The authors declare that they have no competing interests.

\section{Authors' contributions}

$A G, H T, A H, A W$ and TGM conceived the investigation. AG, SY, EA, OK, and AM performed the fieldwork and identified the sand flies. AG, HT, MB, AH, TGM and AW analyzed the data and prepared the manuscript. All authors read and approved the final manuscript.

\section{Acknowledgements}

This study was supported by the Bill and Melinda Gates Foundation Global Health Program (grant number OPPGH5336). We gratefully thank our field assistants Haile Gebremariam and Bisrat Tadesse, and our driver Kibrom Tafere for their help with collection and processing of sand fly specimens.

\section{Author details}

'Department of Zoological Sciences, Addis Ababa University, Addis Ababa, Ethiopia. ${ }^{2}$ Department of Biology, College of Natural Science, Jigjiga University, Jigjiga, Ethiopia. ${ }^{3}$ Department of Microbiology and Molecular Genetics, The Institute of Medical Research Israel-Canada The Kuvin Center for the Study of Infectious and Tropical Diseases, Faculty of Medicine, The Hebrew University, Hadassah Medical School, Jerusalem, Israel. ${ }^{4}$ Aklilu Lemma Institute of Pathobiology, Addis Ababa University, Addis Ababa, Ethiopia. ${ }^{5}$ Department of Microbiology, Immunology and Parasitology, College of Health Sciences, Addis Ababa University, Addis Ababa, Ethiopia. 
Received: 6 December 2014 Accepted: 17 March 2015 Published online: 31 March 2015

\section{References}

1. Desjeux P. Leishmaniasis: current situation and new perspectives. Comp Imunnol Microbiol Infect Dis. 2004;27:305-18.

2. Alvar J, Vélez ID, Bern C, Herrero M, Desjeux P, Cano J, et al. Leishmaniasis worldwide and global estimates of its incidence. PLoS One. 2012;7:e35671.

3. Lyons S, Veeken H, Long J. Visceral leishmaniasis and HIV in Tigray, Ethiopia. Trop Med Int Health. 2003;2003(8):733-9.

4. Hailu A, Gebre-Michael T, Berhe N, Balkew M. Leishmaniasis in Ethiopia. In: Berhane Y, Haile-Mariam D, Kloos H, editors. The ecology and epidemiology of health and disease in Ethiopia. 1st ed. Addis Ababa: Shama Books; 2006. p. 615-34.

5. Alvar J, Bashaye S, Argaw D, Cruz I, Aparicio P, Kassa A, et al. Kala-azar outbreak in Libo Kemkem, Ethiopia: epidemiologic and parasitologic assessment. Am J Trop Med Hyg. 2007;77:275-82.

6. Abbasi I, Aramin S, Hailu A, Shiferaw W, Kassahun A, Belay S, et al. Evaluation of PCR procedures for detecting and quantifying Leishmania donovani DNA in large numbers of dried human blood samples from a visceral leishmaniasis focus in Northern Ethiopia. BMC Infect Dis. 2013;13:153.

7. Killick-Kendrick R. The biology and control of phlebotomine sand flies. Clin Dermatol. 1999;17:279-89.

8. Maroli M, Feliciangeli MD, Bichaud L, Charrel RN, Gradoni L. Phlebotomine sand flies and the spreading of leishmaniases and other diseases of public health concern. Med Vet Entomol. 2013;27:123-47.

9. Perkins PV, Githure Jl, Mebrahtu Y, Kiilu G, Anjili C, Ngumbi PS, et al. Isolation of Leishmania donovani from Phlebotomus martini in Baringo District, Kenya. Trans R Soc Trop Med Hyg. 1988;82:695-700.

10. Gebre-Michael T, Lane R. The roles of Phlebotomus martini and P. ceiiae (Diptera: Phiebotominae) as vectors of visceral leishmaniasis in the Aba Roba focus, southern Ethiopia. Med Vet Entomol. 1996;10:53-62.

11. Hoogstraal H, Heyneman D. Leishmaniasis in the Sudan Republic: 30 . Final epidemiologic report. Am J Trop Med Hyg. 1969;18:1091-210.

12. Elnaiem DA, Ward RD, Hassan HK, Miles MA, Frame LA. Infection rates of Leishmania donovani in Phlebotomus orientalis from a focus of visceral leishmaniasis in eastern Sudan. Ann Trop Med Parasitol. 1998;92:229-32.

13. Gebre-Michael T, Balkew M, Berhe N, Hailu A, Mekonnen Y. Further studies on the phlebotomine sand flies of the kala-azar endemic lowlands of Humera-Metema (north-west Ethiopia) with observations on their natural bloodmeal sources. Parasit Vect. 2010;3:6.

14. Ngumbi PM, Lawyer PG, Johnson RN, Kiilu G, Asiago C. Identification of sand fly blood meals from Baringo district, Kenya, by direct enzyme linked immunosorbent assays (ELISA). Med Vet Entomol. 1992;6:385-8.

15. Bongiorno G, Habluetzel A, Khoury C, Maroli M. Host preference of phlebotomine sand flies at a hypoendemic focus of canine leishmaniasis in central Italy. Acta Trop. 2003;88:109-16.

16. Abbasi I, Cunio R, Warburg A. Identification of bloodmeals imbibed by phlebotomine sand flies using cytochrome $b$ PCR and reverse line blotting. Vect Borne Zoon Dis. 2009;9:79-86.

17. Garlapati RB, Abbasi I, Warburg A, Poché D, Poché R. Identification of bloodmeals in wild caught blood fed Phlebotomus argentipes (Diptera: Psychodidae) using cytochrome $b$ PCR and reverse line blotting in Bihar, India. J Med Entomol. 2012;49:515-21.

18. Johnson RN, Ngumbi PM, Mwanyumba JP, Roberts CR. Host feeding preference of Phlebotomus guggisbergi, a vector of Leishmania tropica in Kenya. Med Vet Entomol. 1993;7:216-8.

19. Montoya-lerma J, Lane RP. Factors affecting host preference of Lutzomia evansi (Diptera: Psychodidae) a vector of visceral leishmaniasis in Colombia. Bull Entomol Res. 1996;86:43-50.

20. Hassan MM, Osman OF, Raba'a FMA, Schallig HDFH, Elnaiem DA. Role of the domestic dog as a reservoir host of Leishmania donovani in eastern Sudan. Parasit Vect. 2009;2:26.

21. Turner ER, Hoogstraal H. Leishmaniasis in the Sudan Republic. 23. Sand flies (Phlebotomus) attracted to rodent-baited traps (Diptera: Psychodidae). J Med Entomol. 1965;2:137-9.

22. Gebresilassie A, Yared S, Aklilu E, Kirstein OD, Moncaz A, Tekie H, et al. The influence of moonlight and lunar periodicity on the efficacy of CDC light trap in sampling Phlebotomus (Larroussius) orientalis (Parrot, 1936) and other
Phlebotomus sand flies (Diptera: Psychodidae) in Ethiopia. Parasit Vect. 2015;8:106.

23. Quate LW. Leishmaniasis in Sudan Republic. 19. Phlebotomus sand flies of the Paloich area in the Sudan (Diptera, Psychodidae). J Med Entomol. 1964;1:19-23.

24. Abonnenc E, Minter DM. Bilingual keys for the identification of the sand flies of the Ethiopian Region (in Fr. and Eng.). Mém Off Rech Sci Tech Outre-Mer Entomol Med. 1965;5:1-63.

25. Lane RP, Fritz GN. The differentiation of the leishmaniasis vector Phlebotomus papatasi from the suspected vector $P$. bergeroti (Diptera: Phlebotominae). Syst Entomol. 1986;11:439-45.

26. Dytham C. Choosing and using statistics. A biologist's guide. 3rd ed. UK: Wiley-Blackwell. A John Wiley \& Sons, Ltd; 2011.

27. Quinnell RJ, Dye C, Shaw JJ. Host preferences of the phlebotomine sand fly Lutzomyia longipalpis (Diptera: Psychodidae) in Amazonian Brazil. Med Vet Entomol. 1992;6:195-200.

28. Hamilton JGC, Ramsoondar TMC. Attraction of Lutzomyia longipalpis to human skin odors. Med Vet Entomol. 1994;8:375-80.

29. Adler GH, Becerra MT, Travi BL. Feeding success of Lutzomyia evansi (Diptera: Psychodidae) experimentally exposed to small mammal hosts in an endemic focus of Leishmania chagasi in northern Colombia. Biomedica. 2003;23:396-400

30. Mutinga MJ, Kyai PM, Kamau C, Omogo DM. Epidemiology of leishmaniasis in Kenya. III. Host preference studies using various types of animal baits at animal burrows in Marigat, Baringo District. Insect Sci Applic. 1986;7:191-7.

31. Bern CA, Hightower W, Chowdhury R, Ali M, Amann J, Wagatsuma Y, et al. Risk factors for kala-azar in Bangladesh. Emerg Infect Dis. 2005;11:655-62.

32. Barnett PG, Singh SP, Bern C, Hightower AW, Sundar S. Virgin soil: the spread of visceral leishmaniasis into Uttar Pradesh, India. Am J Trop Med Hyg. 2005;73:720-5.

33. Mukhtar MM, Sharief AH, el Saffi SH, Harith AE, Higazzi TB, Adam AM, et al. Detection of antibodies to Leishmania donovani in animals in a kala-azar endemic region in eastern Sudan: a preliminary report. Trans Roy Soc Trop Med Hyg. 2000;94:33-6.

34. Bhattarai NR, Van der Auwera G, Rijal S, Picado A, Speybroeck N, Khanal B, et al. Domestic animals and epidemiology of visceral leishmaniasis, Nepal. Emerg Infect Dis. 2010;16:231-7.

35. Elnaiem DA, Elnahas AM, Aboud MA. Protective efficacy of lambdacyhalothrin-impregnated bednets against Phlebotomus orientalis, the vector of visceral leishmaniasis in Sudan. Med Vet Entomol. 1999;13:310-4.

36. Campbell-Lendrum DH, Pinto MC, Brandä̈-Filho SP, de Souza AA, Ready PD, Davies CR. Experimental comparison of anthropophily between geographically dispersed populations of Lutzomyia whitmani. J Med Entomol. 1999;13:299-309.

37. Anjili CO, Ngichabe CK, Mbati PA, Lugalia RM, Wamwayi HM, Githure J. Experimental infection of domestic sheep with culture derived Leishmania donovani promastigotes. Vet Parasitol. 1988;74:315-8.

38. Anjili CO, Ngumbi PM, Irungu LW. Natural and experimental studies on domestic animal infections with visceral and cutaneous leishmaniases in Kenya. Afr J Health Sci. 2012;23:292-7.

39. Mamo H. Production of specific antisera against selected mammals and identification of blood meals of phlebotomine sand flies transmitting visceral leishmaniasis in Ethiopia, MSc thesis. Addis Ababa: Addis Ababa University, Biology Department; 1999.

40. Svobodová M, Sádlová J, Chang KP, Volf P. Distribution and feeding preference of sand flies Phlebotomus sergenti and P. papatasi in the cutaneous leishmaniasis focus of Sanliurfa, Turkey. Am J Trop Med Hyg. 2003;68:6-9.

41. World Health Organization Expert Committee (WHO). Control of the leishmaniases. Report of a meeting of the WHO Expert Committee on the control of leishmaniases. Geneva: WHO Technical Report Series; 2010. p. 949.

42. De Lima H, De Guglielmo Z, Rodrguez A, Convit J, Rodriguez N. Cotton rats (Sigmodon hispidus) and black rats (Rattus rattus) as possible reservoirs of Leishmania spp. in Lara State, Venezuela. Mem Inst Oswaldo Cruz, Rio de Janeiro. 2002;97:169-74.

43. Mehrabani D, Motazedian MH, Oryan A, Asgaril Q, Hatam GR, Karamian M. A search for the rodent hosts of Leishmania major in the Larestan region of southern Iran: demonstration of the parasite in Tatera indica and Gerbillus sp., by microscopy, culture and PCR. Ann Trop Med Parasil. 2007;101:315-22.

44. Molina R, Jimenez MI, Cruz I, Iriso A, Martín-Martín I, Sevillano O, et al. The hare (Lepus granatensis) as potential sylvatic reservoir of Leishmania infantum in Spain. Vet Parasitol. 2012;190:268-71. 
45. Moreno I, Alvarez J, García N, de la Fuente S, Martínez I, Marino E, et al. Detection of anti-Leishmania infantum antibodies in sylvatic lagomorphs from an epidemic area of Madrid using the indirect immunofluorescence antibody test. Vet Parasitol. 2013;199:264-7.

46. Palit A, Kesari S, Ranjan A, Kishore K. Mating aggregation of Phlebotomus argentipes at animal hosts in India. Indian J Parasitol. 1993;17:11-3.

47. Lane RP, Pile MM, Amerasinghe EP. Anthiopophagy and aggregation behavior of the sand fly Phlebotomus argentipes in Sri Lanka. Med Vet Entomol. 1990;4:79-88.

48. Jarvis EK, Rutledge LC. Laboratory observations on mating and leck like aggregations in Lutzomyia longipalpis (Diptera: Psychodidae). J Med Entomol. 1992;29:171-7.

49. Warburg A, Faiman R. Research priorities for the control of phlebotomine sand flies. J Vec Ecol. 2011;36:10-6.

\section{Submit your next manuscript to BioMed Central and take full advantage of:}

- Convenient online submission

- Thorough peer review

- No space constraints or color figure charges

- Immediate publication on acceptance

- Inclusion in PubMed, CAS, Scopus and Google Scholar

- Research which is freely available for redistribution 